\title{
Comportamento ingestivo de bovinos leiteiros alimentados com farelo de crambe
}

\author{
[Ingestive behavior of dairy catle fed crambe bran] \\ K.M. Oliveira ${ }^{1}$, G.H.F. Castro ${ }^{1}$, B.N. Herculano ${ }^{1}$, M.H.F. Mourthé2, \\ R.A. Santos ${ }^{1}$, A.V. Pires ${ }^{1}$ \\ ${ }^{1}$ UFVJM - Diamantina, MG \\ ${ }^{2} \mathrm{UFMG}$ - Montes Claros, MG
}

\begin{abstract}
RESUMO
O objetivo deste trabalho foi estudar os efeitos da utilização de farelo de crambe em substituição ao farelo de soja sobre o comportamento ingestivo de bovinos leiteiros. Foram utilizados quatro machos castrados Holandês x Zebu, fistulados no rúmen, com peso vivo médio de $664 \mathrm{~kg}$, distribuídos em delineamento quadrado latino $4 \mathrm{x} 4$. Os tratamentos consistiram em quatro dietas isoproteicas e isoenergéticas, formuladas com relação volumoso:concentrado 60:40 com base na matéria seca (MS). O volumoso foi composto de silagem de milho (51\% MS) e feno de Tifton (49\% MS), e o concentrado formulado com níveis crescentes de substituição do farelo de soja pelo farelo de crambe em $0 \%, 2,8 \%, 6,4 \%$ e $11,0 \%$ na MS da dieta. O comportamento ingestivo foi avaliado por meio do método direto de avaliação visual, em intervalos de 10 minutos, durante períodos de 24 horas. Registraram-se a frequência de alimentação, a ruminação e o ócio, bem como a posição do animal (em pé ou em decúbito). As variáveis em pé e em decúbito não diferiram entre os tratamentos, assim como os tempos gastos em alimentação, ruminação e ócio. O consumo de matéria seca e de FDN expressos em g/dia e gFDN/dia, respectivamente, a eficiência de ruminação expressa em gMS/min, a eficiência de ruminação expressa em gFDN/dia e o tempo de mastigação total não diferiram significativamente. No entanto, a eficiência de alimentação (gMS/min) variou de forma linear decrescente com a inclusão do farelo de crambe. Os períodos do dia influenciaram todas as atividades. O maior tempo de alimentação foi observado nos períodos após o fornecimento da dieta, e a maior atividade de ruminação foi verificada no período noturno. A substituição de farelo de soja por farelo de crambe não afetou o comportamento ingestivo, exceto para o parâmetro eficiência de alimentação. Nesse sentido, considerando o comportamento ingestivo, recomenda-se a substituição do farelo de soja por farelo de crambe para alimentação de bovinos leiteiros.
\end{abstract}

Palavras-chave: consumo, coproduto, Crambe abysinica, eficiência alimentar, ruminação

\begin{abstract}
The aim of this work was to study the effects of the use of crambe meal replacing soy bean meal on the ingestive behavior of dairy cattle. Four male Holstein x Zebu rumen, with average live weight of $664 \mathrm{~kg}$ distributed in a $4 \times 4$ latin square design. The treatments consisted of four isonitrogenous and isocaloric diets, formulated with a roughage:concentrate ratio of 60:40 based on dry matter (DM). The forage was corn silage (51\% DM) and Tifton grass hay (49\% DM), and the concentrate was formulated with increasing levels of substitution of soy bean meal by crambe meal at $0 \%, 2.8 \%, 6.4 \%$ and $11.0 \%$ of the diet DM. The feeding behavior was evaluated using the direct method of visual assessment in 10 minute intervals during a 24 hour period. The frequency of feeding, idling time and the animal's position (standing or supine) were recorded. The variables standing and supine did not differ between treatments as well as time spent feeding, ruminating and idling times. The consumption of dry matter and NDF expressed in g/day and gNDF/day respectively, the efficiency of rumination expressed in $g D M / m i n$, the efficiency of rumination expressed in gNDF/day and the total chewing time did not differ significantly.
\end{abstract}

Recebido em 18 de setembro de 2014

Aceito em 28 de agosto de 2015

E-mail: keniamoliveira@yahoo.com.br 
However, the efficiency of power ( $g D M / m i n)$ decreased linearly with the inclusion of crambe meal. Periods of the day influenced all the activities. The longer feeding time was observed in the periods after the diet intake and greater rumination activity was observed at night. The replacement of soy bean meal by meal crambe did not affect feeding behavior, except for the feeding efficiency parameter. In this sense, considering the feeding behavior, the replacement of soy bean meal by crambe meal to feed dairy cattle is recommended.

Keywords: by-product, Crambe abysinica, consumption, feed efficiency, rumination

\section{INTRODUÇÃO}

A nutrição corresponde à maior parcela dos custos nos sistema de produção animal. O desenvolvimento de estratégias para a redução desses custos, associado à necessidade de disponibilizar ao animal alimento de qualidade, independentemente da época do ano, é de extrema relevância para otimizar a cadeia produtiva do leite e da carne bovina.

O estudo dos padrões de comportamento ingestivo dos bovinos é importante ferramenta que possibilita ajustar as instalações, as técnicas de manejo e a alimentação, proporcionando melhorias no desempenho e nos índices zootécnicos (Mendonça et al., 2004). O comportamento dos ruminantes pode ser caracterizado, basicamente, pela sucessão de três atividades básicas: alimentação, ruminação e ócio, atividades essas que podem ser influenciadas por fatores como dieta, manejo, condições ambientais e atividade dos animais do mesmo grupo (Fisher et al., 1997). Além disso, os horários de fornecimento das rações tendem a influenciar os picos de ocorrência das atividades ingestivas (Oliveira et al., 2012).

Considerando que as indústrias produtoras de biodiesel geram grandes quantidades de resíduos (tortas e farelos) resultantes da extração do óleo, com provável potencial de utilização na alimentação animal, os quais podem ser caracterizados como coprodutos da agroindústria, o crambe (Crambe abysinica) desponta no cenário nacional como uma das oleaginosas mais promissoras para a produção de biodiesel, devido principalmente ao elevado teor de óleo presente nessa leguminosa, cerca de $34 \%$ a 38\% (Cardoso et al., 2012).

A avaliação do comportamento ingestivo de animais alimentados com dietas contendo inclusão/substituição de coprodutos agroindustriais pode contribuir para detectar os potenciais efeitos de fatores antinutricionais, já que eles podem alterar os tempos despendidos em alimentação e, consequentemente, em ócio e ruminação (Dado e Allen, 1995).

Diante do exposto, o objetivo deste trabalho foi avaliar o comportamento ingestivo de bovinos recebendo dietas com substituição crescente do farelo de soja por farelo de crambe.

\section{MATERIAL E MÉTODOS}

O experimento foi conduzido na Fazenda Experimental do Moura, situada no município de Curvelo, Minas Gerais, pertencente à Universidade Federal dos Vales do Jequitinhonha e Mucuri, entre agosto e dezembro de 2012. Este experimento foi registrado e aprovado pelo CEUA/UFVJM, sob o número de protocolo $002 / 2012$.

Foram utilizados quatro machos castrados Holandês x Zebu fistulados no rúmen, com peso médio de $664 \mathrm{~kg}$. O delineamento utilizado foi quadrado latino repetido no tempo, com duas repetições e períodos experimentais de 13 dias, sendo os oito primeiros dias de adaptação à dieta e cinco dias de coleta dos dados de consumo. $\mathrm{O}$ último dia do período experimental foi utilizado para observação do comportamento. Os animais foram alojados em baias individuais providas de cochos para alimentação, água e suplemento mineral, bem como cama de areia, a qual era limpa diariamente. Os animais tinham acesso, por duas horas, a uma área de passeio de $100 \mathrm{~m}^{2}$ para movimentação.

As dietas foram formuladas segundo o NRC (2001), de forma a serem isoproteicas e isoenergéticas e a atenderem as exigências de mantença, seguindo a relação volumoso:concentrado de 60:40, respectivamente, com base na matéria seca (MS). A fração de volumoso da dieta consistiu de silagem de milho e feno de Tifton, seguindo 
proporções predeterminadas de $33 \%$ e $67 \%$, respectivamente, com base na MS. Os animais receberam quatro dietas contendo $0 \%, 2,8 \%$, $6,4 \%$ e $11,0 \%$ de farelo de crambe (FC) na MS da dieta, o qual representava a substituição do farelo de soja (FS) em $0 \%, 33 \%, 66 \%$ e $99 \%$ por FC na MS da dieta (Tab. 1, 2 e 3).

Tabela 1. Composição percentual dos ingredientes utilizados nas dietas com base na matéria natural

\begin{tabular}{lcccc} 
& \multicolumn{4}{c}{ Níveis de inclusão de crambe (\%) } \\
\cline { 2 - 5 } \multicolumn{1}{c}{ Ingrediente } & 0 & 33 & 66 & 99 \\
\hline Silagem de milho & 43,4 & 43,0 & 42,5 & 42,0 \\
Feno de Tifton 85 & 30,1 & 29,8 & 29,5 & 29,1 \\
Farelo de soja & 9,1 & 6,7 & 3,8 & 0,1 \\
Farelo de crambe & 0,00 & 3,2 & 7,1 & 12,1 \\
Fubá de milho & 14,4 & 14,3 & 14,0 & 13,8 \\
Suplemento vitamínico mineral $^{1}$ & 3,1 & 3,1 & 3,0 & 3,0 \\
\hline
\end{tabular}

${ }^{\mathrm{I}}$ Composição:carbonato de cálcio; cloreto de potássio; cloreto de sódio (sal comum); enxofre ventilado (flor de enxofre); fosfato bicálcico; óxido de magnésio; carboaminofosfoquelato de cobre; carboaminofosfoquelato de cromo; carboaminofosfoquelato de enxofre; carboaminofosfoquelato de ferro; carboaminofosfoquelato de manganês; carboaminofosfoquelato de selênio; carboaminofosfoquelato de zinco; hidróxido de tolueno butilado (BHT); iodato de cálcio; monóxido de manganês; selenito de sódio; sulfato de cobalto; sulfato de cobre mono-hidratado; sulfato de zinco; vitamina A; vitamina D3; vitamina E.

Tabela 2. Composição nutricional dos ingredientes das dietas experimentais

\begin{tabular}{cccccc}
\hline Itens & Silagem & Feno & Milho moído & Farelo de soja & Farelo de crambe \\
\hline MS (\%) & 29,04 & 87,75 & 83,98 & 94,67 & 91,75 \\
MM (\%MS) & 6,10 & 8,03 & 1,56 & 6,36 & 6,28 \\
PB (\%MS) & 6,63 & 9,21 & 8,38 & 44,39 & 32,26 \\
EE (\%MS) & 2,60 & 2,41 & 4,80 & 2,36 & 0,31 \\
PIDN (\%PB) & 16,40 & 23,09 & 21,91 & 2,83 & 14,17 \\
PIDA (\%PB) & 15,70 & 14,73 & 5,94 & 0,90 & 5,94 \\
FDNcp (\%MS) & 61,20 & 63,19 & 21,83 & 12,32 & 27,98 \\
FDAcp (\%MS) & 28,20 & 26,87 & 1,64 & 6,32 & 16,70 \\
CNF (\%MS) $^{23,46}$ & 17,16 & 63,43 & 34,57 & 33,17 \\
NDT $^{1}$ & 57,23 & 55,62 & 87,24 & 81,54 & 58,00 \\
\hline
\end{tabular}

$\mathrm{MS}=$ matéria seca; $\mathrm{MM}=$ matéria mineral; $\mathrm{PB}=$ proteína bruta; $\mathrm{EE}=$ extrato etéreo; $\mathrm{PIDN}=$ proteína insolúvel em detergente neutro; $\mathrm{PIDA}=$ proteína insolúvel em detergente ácido; $\mathrm{FDNcp}=$ fibra em detergente neutro corrigido para cinzas e proteína; $\mathrm{FDAcp}=$ fibra em detergente ácido corrigido para cinzas e proteína; $\mathrm{CNF}=$ carboidratos não fibrosos; NDT= nitrogênio digestível total. ${ }^{1}$ Valor obtido a partir de valores médios encontrados na literatura.

Tabela 3. Composição nutricional das dietas experimentais

\begin{tabular}{ccccc}
\hline \multirow{2}{*}{ Itens } & \multicolumn{4}{c}{ Níveis de inclusão de farelo de crambe } \\
\cline { 2 - 4 } & 0FC & $33 \mathrm{FC}$ & $66 \mathrm{FC}$ & $99 \mathrm{FC}$ \\
MS (\%) & 68,42 & 66,85 & 66,21 & 65,41 \\
MM (\%MS) & 11,87 & 11,42 & 12,99 & 12,24 \\
PB (\%MS) & 13,65 & 13,50 & 13,44 & 13,38 \\
EE (\%MS) & 2,75 & 2,72 & 2,58 & 2,74 \\
PIDN (\%PB) & 12,15 & 15,11 & 15,25 & 15,89 \\
PIDA (\%PB) & 4,92 & 5,43 & 5,47 & 5,56 \\
FDNcp (\%MS) & 45,17 & 44,69 & 48,05 & 45,71 \\
FDAcp (\%MS) & 18,41 & 19,14 & 21,20 & 21,62 \\
CNF (\%MS) & 26,57 & 25,81 & 24,98 & 24,88 \\
NDT (\%MS) & 62,80 & 65,10 & 63,90 & 62,50 \\
LIG (\%) & 11,29 & 12,35 & 13,11 & 15,87 \\
\hline
\end{tabular}


O arraçoamento foi realizado duas vezes ao dia, às oito e às 16 horas. Diariamente, as sobras foram pesadas a fim de se ajustar o consumo para que houvesse $10 \%$ de sobra ao dia. As amostras diárias das sobras de cada animal e da dieta fornecida eram acondicionadas em sacos plásticos e armazenadas a $-10^{\circ} \mathrm{C}$. Ao final do experimento, as amostras individuais das sobras e das dietas oferecidas foram homogeneizadas por animal/período, sendo, então, pré-secas a $50^{\circ} \mathrm{C}$, moídas em moinho de peneira de $1 \mathrm{~mm}$ de malha, acondicionadas e armazenadas para análises posteriores.

As dietas e as sobras amostradas foram analisadas no Laboratório de Nutrição Animal (LNA) do Departamento de Zootecnia da Universidade Federal dos Vales do Jequitinhonha e Mucuri - UFVJM quanto aos teores de matéria seca (MS), matéria mineral $(\mathrm{MM})$, proteína bruta (PB), fibra em detergente neutro (FDN), fibra em detergente ácido (FDA), extrato etéreo (EE), proteína insolúvel em detergente neutro (PIDN) e proteína insolúvel em detergente ácido (PIDA) foram determinadas segundo metodologias propostas por Detmann et al. (2012). Os carboidratos totais (CT), carboidratos não fibrosos (CNF) e nutrientes digestíveis totais (NDT) foram calculados segundo Sniffen et al. (1992): CT = $100-(\%$ PB $+\% \mathrm{EE}+\%$ CINZAS) $\mathrm{CNF}=\mathrm{CT}-\mathrm{FDN}$; NDT $=\mathrm{PB}$ digestível $+(\mathrm{EE}$ digestível $\times 2,25)+\mathrm{FDN}$ digestível + CNF digestível.

O cálculo de consumo foi feito descontando-se as sobras $(\% \mathrm{MS})$ do que era fornecido (\% MS) de cada nutriente.

A avaliação do comportamento ingestivo foi realizada no $13^{\circ}$ dia de cada período, totalizando oito avaliações. As observações visuais foram realizadas com intervalos de 10 minutos, em períodos de 24 horas seguidas, iniciando-se às oito horas, após o arraçoamento dos animais. O ambiente foi mantido com iluminação artificial indireta e parcial, ou seja, somente no corredor e não nas baias, para possibilitar uma melhor adaptação dos animais e a observação noturna. Nas avaliações, foram consideradas as atividades comportamentais de consumo, ruminação, ingestão de água, ócio, bem como a posição do animal, se em pé ou deitado.
Para monitoramento diário do ambiente, utilizaram-se dois conjuntos de termohigrômetros digitais. Os dois conjuntos foram dispostos à meia altura do corpo dos animais, em extremidades opostas ao alojamento dos animais. Os dados obtidos por meio do monitoramento ambiental foram empregados no cálculo do índice de temperatura e umidade (ITU) proposto por Buffington et al. (1982).

As variáveis determinadas com base no comportamento ingestivo foram obtidas conforme descritas em Bürger et al. (2000):

$\mathrm{EAL}=\mathrm{CMS} / \mathrm{TAL}$;

$\mathrm{ERU}=\mathrm{CMS} / \mathrm{TRU}$

ERUFDN $=$ CFDN/TRU;

$\mathrm{TMT}=\mathrm{TAL}+\mathrm{TRU}$

em que: EAL (gMS/h) é eficiência de alimentação; CMS (gMS/dia), consumo de MS; TAL (min/dia), tempo de alimentação; ERU (gMS/min; gFDN/min), eficiência de ruminação; TRU (min/dia), tempo de ruminação; CFDN(gFDN/dia), consumo de FDN; TMT (min/dia), tempo de mastigação total.

O comportamento ingestivo diário e as variáveis derivadas do comportamento ingestivo diário foram analisados segundo o modelo estatístico descrito:

$$
\mathrm{Y}_{\mathrm{iwzjk}}=\mu+\mathrm{Q}_{\mathrm{w}}+\mathrm{D}_{\mathrm{z}}+\mathrm{A}_{\mathrm{j}} / \mathrm{Q}_{\mathrm{w}}+\mathrm{P}_{\mathrm{k}} / \mathrm{Q}_{\mathrm{w}}+\mathrm{e}_{\mathrm{iwzjk}}
$$

em que: $Y_{\text {iwzjk }}$ observação "i" no quadrado "w" da dieta " $\mathrm{z}$ " do animal " $\mathrm{j}$ " no período " $\mathrm{k}$ "; $\mu=$ média geral; $\mathrm{Q}_{\mathrm{w}}=$ efeito de quadrado latino $(\mathrm{w}=1$ e 2); $\mathrm{D}_{\mathrm{i}}=$ efeito da dieta "i", (i = FC0, FC33, FC66 e FC99); $A_{j} / Q_{w}=$ efeito do animal "j" $(j=1$, $2,3,4)$ dentro do quadrado "w"; $\mathrm{P}_{\mathrm{k}} / \mathrm{Q}_{\mathrm{w}}=$ efeito do período "k" $(1,2,3,4)$ dentro do quadrado "w"; $\mathrm{e}_{\mathrm{ijkw}}=$ erro experimental.

Esses dados experimentais foram submetidos à análise de variância, e determinaram-se as equações de regressão com probabilidade de erro de 5\% com auxílio do software SAS 9.0 (2002).

Para avaliação do comportamento ingestivo durante os períodos do dia, as observações foram agrupadas em intervalos de tempo de quatro horas a partir do fornecimento da dieta durante o período da manhã, totalizando seis períodos durante o dia. 
Os dados e as variáveis do comportamento ingestivo considerando os intervalos de tempo de quatro horas foram analisados segundo o modelo estatístico descrito:

$$
\begin{gathered}
\mathrm{Y}_{\mathrm{iwzjk}}=\mu+\mathrm{Q}_{\mathrm{w}}+\mathrm{D}_{\mathrm{z}}+\mathrm{A}_{\mathrm{j}} / \mathrm{Q}_{\mathrm{w}}+\mathrm{P}_{\mathrm{k}} / \mathrm{Q}_{\mathrm{w}}+\mathrm{T}_{\mathrm{h}}+ \\
\mathrm{T}_{\mathrm{h}} \mathrm{XD}_{\mathrm{i}}+\mathrm{e}_{\mathrm{iwzjk}},
\end{gathered}
$$

em que: $Y_{\text {iwzjk }}$ observação "i" no quadrado "w" da dieta " $\mathrm{z}$ " do animal "j" no período " $\mathrm{k}$ “; $\mu=$ média geral; $\mathrm{Q}_{\mathrm{w}}=$ efeito de quadrado latino $(\mathrm{w}=1$ e 2); $\mathrm{D}_{\mathrm{i}=}$ efeito da dieta "i" (i = FC0, FC33, FC66 e FC99); $A_{j} / Q_{w}=$ efeito do animal "j" ( $j=1,2,3$, 4) dentro do quadrado "w"; $P_{k} / Q_{w}=$ efeito do período "k" $(1,2,3,4)$ dentro do quadrado "w"; $\mathrm{T}_{\mathrm{h}}=$ efeito do intervalo de tempo " $\mathrm{h}$ ", $(\mathrm{h}=1,2$, $3,4,5,6) ; \mathrm{T}_{\mathrm{h}} \mathrm{xD}_{\mathrm{i}}=$ efeito da interação tempo e dieta; $\mathrm{e}_{\mathrm{ijkw}}=$ erro experimental.

Os dados experimentais obtidos nos tratamentos e períodos do dia foram submetidos às análises de variância para avaliação da interação entre essas fontes de variação, e as médias foram comparadas pelo teste de SNK com probabilidade de erro de 5\% com auxílio do software SAS 9.0 (2002).

\section{RESULTADOS E DISCUSSÃO}

Fatores climáticos podem interferir, negativamente, no padrão de comportamento ingestivo, causando prejuízos no desempenho animal. No presente trabalho, os valores médios de temperatura, umidade e ITU obtidos foram $25,35^{\circ} \mathrm{C}, 60,98 \%$ e 53,24 , respectivamente. De modo geral, esses resultados são considerados dentro da faixa de normalidade, demonstrando, assim, que os animais encontravam-se em situação de conforto térmico.

Não foi verificado efeito $(\mathrm{P} \geq 0,05)$ de tratamento nos valores médios obtidos para as posições em pé e em decúbito (Tab. 4). O maior tempo de permanência do animal em posição de decúbito, quando comparado com o tempo em pé, demonstra uma condição de conforto e bem-estar animal (Marques, 2005).

Tabela 4. Valores médios do tempo em minutos em pé ou em decúbito e nas atividades de alimentação, ruminação e ócio de bovinos alimentados com farelo de crambe, em substituição ao farelo de soja

\begin{tabular}{lccccccc}
\hline \multirow{2}{*}{\multicolumn{1}{c}{ Itens }} & \multicolumn{2}{c}{ Níveis de inclusão de farelo de crambe } & \multirow{2}{*}{ Equação } & \multirow{2}{*}{$\mathrm{P}$} & \multirow{2}{*}{ CV(\%) } \\
\cline { 2 - 4 } & 0FC & 33FC & $66 \mathrm{FC}$ & $99 \mathrm{FC}$ & & & \\
\hline Em pé & 596,0 & 641,0 & 630,0 & 599,0 & $\hat{\mathrm{Y}}=616,5$ & 0,9873 & 11,9 \\
Deitado & 844,0 & 799,0 & 810,0 & 842,0 & $\hat{\mathrm{Y}}=823,8$ & 0,9873 & 8,2 \\
Alimentação & 249,0 & 268,0 & 294,0 & 284,0 & $\hat{\mathrm{Y}}=273,8$ & 0,0697 & 10,6 \\
Ruminação & 492,0 & 499,0 & 484,0 & 502,0 & $\hat{\mathrm{Y}}=494,3$ & 0,8602 & 7,7 \\
Ócio & 699,0 & 673,0 & 662,0 & 654,0 & $\hat{\mathrm{Y}}=672,0$ & 0,0761 & 7,3 \\
\hline
\end{tabular}

Níveis de substituição de $\mathrm{FS}$ por $\mathrm{FC}$ : $0 \mathrm{FC}=0 \%, 33 \mathrm{FC}=2,8 \%, 66 \mathrm{FC}=6,4 \%$ e $99 \mathrm{FC}=11,0 \%$ de $\mathrm{FC}$ na MS da dieta.

O tempo gasto com alimentação (Tab. 4) não foi influenciado $(\mathrm{P} \geq 0,05)$ pelos tratamentos. Com tempo médio em alimentação de 273,8 minutos, esses valores foram próximos aos encontrados por Neuman et al. (2009), ao avaliarem o comportamento ingestivo de novilhos confinados recebendo dietas com proporção volumoso:concentrado de 62,7\%:37,3\%, sendo o volumoso utilizado na silagem de milho de diferentes tamanhos de partículas e alturas de corte. Esses autores observaram tempo de alimentação médio de 246,6 minutos.

Os tempos de ruminação e ócio (Tab. 4) não foram influenciados $(\mathrm{P} \geq 0,05)$ pelos tratamentos avaliados. De acordo com Mendonça et al. (2004), o tempo gasto com ruminação em bovinos é altamente correlacionado com o consumo de FDN. Apesar de a dieta com 66\% de FC apresentar maior percentual de FDN, este não foi suficientemente alto para provocar alterações no padrão de ruminação.

O tempo dedicado à ruminação está diretamente relacionado à qualidade e à quantidade de alimento consumido (Mendes et al., 2010). Fatores como aumento no consumo de alimentos e tamanhos menores de partículas tendem a provocar redução nos tempos destinados à ruminação. O tempo de ruminação, encontrado no presente trabalho, foi, em média, 494 minutos/dia, o que corresponde a, aproximadamente, $34 \%$ do tempo, enquanto o tempo destinado à alimentação foi, em média, 274 minutos/dia, aproximadamente 19\% do tempo total. Pazdiora et al. (2011), ao 
avaliarem os efeitos da frequência de fornecimento do volumoso e concentrado no comportamento ingestivo de vacas e novilhas confinadas recebendo dietas com relação volumoso:concentrado de 60:40 na matéria seca, utilizando-se no volumoso a silagem de milho, encontraram que o tempo de ruminação foi de $195,5 \%$ em relação ao tempo dedicado à alimentação, com valores médios de quatro horas e 23 minutos e de oito horas e 25 minutos, respectivamente, sendo o comportamento próximo ao encontrado no presente trabalho, em que o tempo de ruminação foi superior em $180,29 \%$ ao tempo de alimentação.

Os animais permaneceram, em média, $672 \mathrm{~min} /$ dia em ócio, não sendo observada diferença entre os tratamentos $(\mathrm{P} \geq 0,05)$. $\mathrm{O}$ tempo destinado ao ócio é uma variável importante, principalmente para animais de produção, já que, ao permanecer em ócio, os gastos energéticos são reduzidos (Mousquer et al., 2013), pois o animal encontra-se em atividade mínima, e, ao mesmo tempo, metabolizando o alimento ingerido para produção de energia.

Não foi observada diferença significativa $(\mathrm{P} \geq 0,05)$ para a variável consumo de matéria seca $(P \geq 0,05)$ (Tab. 5). Tal fato evidencia que não houve alteração na palatabilidade das dietas, em razão da inclusão dos níveis crescentes de farelo de crambe, sendo valor este acima do recomendado por Valadares Filho et al. (2006), de $12.765 \mathrm{gMS} /$ dia. Esse consumo, acima do previsto, pode ser atribuído ao restabelecimento da condição corporal dos animais durante os primeiros períodos do experimento.

Tabela 5. Consumo voluntário e parâmetros do comportamento ingestivo de bovinos alimentados com farelo de crambe em substituição ao farelo de soja

\begin{tabular}{|c|c|c|c|c|c|c|c|c|}
\hline \multirow{2}{*}{ Itens } & \multicolumn{4}{|c|}{ Níveis de inclusão de farelo de crambe } & \multirow{2}{*}{ Equação } & \multirow{2}{*}{$\mathrm{R}^{2}$} & \multirow{2}{*}{$P$} & \multirow{2}{*}{$\mathrm{CV}$} \\
\hline & OFC & $33 \mathrm{FC}$ & $66 \mathrm{FC}$ & 99FC & & & & \\
\hline CMS & $17.456,3$ & $17.055,0$ & $16.903,8$ & $15.071,3$ & $\hat{Y}=16.621,60$ & -- & 0,8558 & 9,85 \\
\hline CFDN & $7.995,3$ & $8.329,5$ & $8.517,1$ & $7.513,5$ & $\begin{array}{c}\hat{Y}=8.088,84 \\
\hat{Y}=70,43175-\end{array}$ & -- & 0,6631 & 19,28 \\
\hline EAL & 71,3 & 64,0 & 59,8 & 55,2 & $0,15875 \mathrm{x}$ & 0,15 & 0,0307 & 14,56 \\
\hline ERU & 36,1 & 34,4 & 35,3 & 30,4 & $\hat{\mathrm{Y}}=34,06$ & -- & 0,1162 & 12,10 \\
\hline ERUFDN & 16,8 & 16,7 & 17,7 & 15,1 & $\hat{\mathrm{Y}}=16,54$ & -- & 0,4972 & 21,75 \\
\hline TMT & 741,0 & 767,0 & 778,0 & 786,0 & $\hat{\mathrm{Y}}=768,18$ & -- & 0,0759 & 5,86 \\
\hline
\end{tabular}

CMS: consumo de matéria seca em g/dia, CFDN: consumo de FDN em gFDN/dia, EAL: eficiência de alimentação em gMS/min, ERU: eficiência de ruminação em gMS/min, ERUFDN: eficiência de ruminação da FDN em $\mathrm{gFDN} / \mathrm{min}$, TMT: tempo de mastigação total em min/dia.Níveis de substituição de $\mathrm{FS}$ por $\mathrm{FC}$ : $0 \mathrm{FC}=0 \%, 33 \mathrm{FC}=2,8 \%$, $66 \mathrm{FC}=6,4 \%$ e $99 \mathrm{FC}=11,0 \%$ de $\mathrm{FC}$ na MS da dieta.

Não foi observada diferença significativa $(\mathrm{P} \geq 0,05)$ entre os níveis de inclusão de farelo de crambe para a variável CFDN (gFDN/dia) (Tab. 5) com valor médio de $8.088,84 \mathrm{gFDN} / \mathrm{dia}$, provavelmente devido à semelhança nos teores de FDN nas dietas.

Os valores médios para EAL (gMS/min) foram significativos com a inclusão do $\mathrm{FC}(\mathrm{P}<0,05)$ (Tab. 5), apresentando efeito linear decrescente com a inclusão do coproduto entre os níveis estudados $(\hat{\mathrm{Y}}=70,43175-0,15875 \mathrm{x})$. Tal fato, provavelmente, é devido à relação direta com o CMS e o tempo de alimentação, ampliando o padrão numericamente observado para a variável CMS.
Bürger et al. (2000), ao trabalharem com bezerros Holandeses, alimentados com níveis crescentes de concentrado em 30\%, 45\%, 60\%, $75 \%$ e $90 \%$, com base na MS, observaram que a EAL, quando expressa em gMS/hora, registrou crescimento linear, apresentando comportamento oposto ao encontrado no presente trabalho, fato este, provavelmente, devido às diferenças nas proporções volumoso:concentrado e na composição do concentrado.

Não foi observada diferença significativa $(\mathrm{P}>0,05)$ nas variáveis ERU e ERUFDN, com médias de $34,06 \mathrm{gMS} / \mathrm{min}$ e $16,54 \mathrm{gFDN} / \mathrm{min}$, respectivamente (Tab. 5). De acordo com Carvalho (2008), as eficiências de ingestão e de 
ruminação são afetadas, primariamente, pelo consumo animal, que, por sua vez, pode promover alterações nos tempos despendidos na alimentação, na ruminação e no ócio. A semelhança nos tempos de ruminação e no CFDN pode ter contribuído para a não diferenciação na ERU e na ERUFDN.

Mendonça et al. (2004), ao avaliarem os parâmetros do comportamento ingestivo de vacas em lactação puras e mestiças, alimentadas com dietas à base de cana-de-açúcar com relação volumoso:concentrado de 60:40 ou 50:50, ou silagem de milho com relação volumoso:concentrado de 60:40, não encontraram diferença significativa para ERU, expressa em $\mathrm{gMS} / \mathrm{h}$ para as diferentes dietas. No entanto, a ERUFDN, expressa em $\mathrm{gFDN} / \mathrm{h}$, foi maior para a dieta à base de silagem de milho. Ambos os fatores são influenciados pelo teor e pela qualidade da fibra, o que evidencia que não houve alteração deles no presente trabalho.

O TMT, expresso em min/dia, é a soma diária dos tempos despendidos em alimentação e ruminação, ambos influenciados pelo consumo de matéria seca e pelo teor de FDN da dieta. De acordo com Welch (1993), a degradação das partículas durante a mastigação influencia, diretamente, na fermentação bacteriana, ao facilitar o acesso das bactérias, promovendo uma fermentação mais rápida em partículas menores. A variável em questão não apresentou diferença significativa $\quad(\mathrm{P} \geq 0,05)$, com média de $768,18 \mathrm{~min} / \mathrm{dia}$, acompanhando a resposta do tempo gasto em ruminação.

Não houve efeito dos tratamentos nos intervalos de tempo nem interação entre os fatores (tempo e tratamento) sobre as variáveis em pé e em decúbito (Tab. 6). No entanto, houve diferença significativa $(\mathrm{P}<0,05)$ para os intervalos de tempo, em que a maior ocorrência de animais em pé foi registrada no intervalo de 16-20 horas, coincidindo com o horário de fornecimento do alimento no período da tarde. Em contrapartida, a maior incidência de animais na posição em decúbito foi no período de 20-24 horas e de 24quatro horas, quando foram constatadas as temperaturas mais baixas.

A frequência e a duração dos períodos de descanso de animais em confinamento são determinadas pela qualidade da cama. Praticamente metade do tempo que um bovino adulto encontra-se acordado é gasta descansando, normalmente em decúbito, com pés e pernas embaixo do corpo (Degasperi et al., 2003).

Não houve efeito dos tratamentos nos intervalos de tempo, tampouco interação entre os fatores (tempo e tratamento) sobre a variável tempo de alimentação $(\mathrm{P} \geq 0,05)$. No entanto, houve diferença significativa $(\mathrm{P}<0,05)$ para os intervalos de tempo, observando-se maior ocorrência de ingestão de alimentos durante o dia, em que se verificaram dois picos de alimentação bem claros, nos períodos de oito-12 horas e 16-20 horas, momentos esses imediatamente após o fornecimento das dietas. Esse comportamento é mencionado por Oliveira et al. (2012). Segundo esses autores, os horários de fornecimento das dietas tendem a influenciar os picos de ocorrência das atividades ingestivas.

De acordo com Fischer et al. (2000), ruminantes confinados, alimentados duas vezes ao dia, apresentam, como padrão alimentar, duas refeições principais, logo após o arraçoamento (por uma a três horas), e um número variável de pequenas refeições no decorrer do dia.

Não houve efeito dos tratamentos nos intervalos de tempo, tampouco interação entre os fatores (tempo e tratamento) sobre a variável tempo de ruminação $(\mathrm{P} \geq 0,05)$. A ruminação ocorreu, principalmente, no período noturno, concentrando-se entre 20-24 horas e 24-quatro horas da manhã, com valores médios de 121,5 e 116,5 minutos, respectivamente, com um importante pico de 77,5 minutos no início da tarde, no período de 12-16 horas. Pinto et al. (2010) apontaram que o tempo gasto em ruminação é mais elevado no período noturno, fato esse também observado no presente trabalho, o que, segundo Albright (1993), ocorre usualmente na posição deitada. Outro fator que pode ter contribuído para esse comportamento é o possível aumento da produção de calor devido aos processos digestivos, fazendo com que os animais, a fim de manterem a temperatura corporal, realizem essa atividade em horários de temperatura mais amena (Castro, 2012). De acordo com Albrigth (1987), os estímulos da ruminação contribuem para o descanso fisiológico e a recuperação física dos animais. 
Tabela 6. Valores médios do tempo em minutos em pé, em decúbito, alimentando, ruminando e em ócio, nos intervalos de tempo predeterminados de bovinos alimentados com farelo de crambe em substituição ao farelo de soja

\begin{tabular}{|c|c|c|c|c|c|c|c|}
\hline \multirow{3}{*}{ Dieta } & \multicolumn{7}{|c|}{ Intervalos de tempo } \\
\hline & $04 \_08$ & 8_12 & $12 \_16$ & $16 \_20$ & $20 \_24$ & 24_04 & \multirow{2}{*}{$\begin{array}{l}\text { Média dos } \\
\text { tratamentos }\end{array}$} \\
\hline & \multicolumn{6}{|c|}{ Estação } & \\
\hline 0 & 119,0 & 124,0 & 131,0 & 146,0 & 45,0 & 44,0 & 101,5 \\
\hline 33 & 119,0 & 118,0 & 122,0 & 158,0 & 41,0 & 32,0 & 98,3 \\
\hline 66 & 120,0 & 135,0 & 116,0 & 147,0 & 55,0 & 31,0 & 100,7 \\
\hline 99 & 116,0 & 127,0 & 131,0 & 155,0 & 54,0 & 41,0 & 104,0 \\
\hline Média dos períodos & $118,5^{\mathrm{b}}$ & $126,0^{b}$ & $125,0^{b}$ & $151,5^{\mathrm{a}}$ & $48,8^{\mathrm{c}}$ & $37,0^{\mathrm{c}}$ & -- \\
\hline \multicolumn{8}{|c|}{ Decúbito } \\
\hline 0 & 121,0 & 116,0 & 109,0 & 94,0 & 195,0 & 196,0 & 138,5 \\
\hline 33 & 121,0 & 122,0 & 118,0 & 83,0 & 199,0 & 207,0 & 141,7 \\
\hline 66 & 120,0 & 105,0 & 124,0 & 93,0 & 185,0 & 209,0 & 139,3 \\
\hline 99 & 124,0 & 112,0 & 109,0 & 85,0 & 186,0 & 200,0 & 136,0 \\
\hline Média dos períodos & $121,5^{\mathrm{b}}$ & $113,8^{b}$ & $115,0^{\mathrm{b}}$ & $88,8^{\mathrm{c}}$ & $191,3^{\mathrm{a}}$ & $203,0^{\mathrm{a}}$ & -- \\
\hline \multicolumn{8}{|c|}{ Alimentação } \\
\hline 0 & 21,0 & 95,0 & 49,0 & 90,0 & 14,0 & 28,0 & 49,5 \\
\hline 33 & 14,0 & 89,0 & 33,0 & 90,0 & 6,0 & 11,0 & 40,5 \\
\hline 66 & 14,0 & 105,0 & 34,0 & 84,0 & 14,0 & 7,0 & 43,0 \\
\hline 99 & 17,0 & 106,0 & 55,0 & 89,0 & 14,0 & 14,0 & 49,2 \\
\hline Média dos períodos & $16,5^{\mathrm{c}}$ & $98,8^{\mathrm{a}}$ & $42,8^{b}$ & $88,3^{\mathrm{a}}$ & $12,0^{\mathrm{c}}$ & $15,0^{\mathrm{c}}$ & -- \\
\hline \multicolumn{8}{|c|}{ Ruminação } \\
\hline 0 & 62,0 & 62,0 & 73,0 & 62,0 & 114,0 & 108,0 & 80,2 \\
\hline 33 & 58,0 & 54,0 & 86,0 & 61,0 & 123,0 & 115,0 & 82,8 \\
\hline 66 & 68,0 & 56,0 & 76,0 & 64,0 & 131,0 & 124,0 & 86,5 \\
\hline 99 & 61,0 & 61,0 & 75,0 & 57,0 & 118,0 & 119,0 & 81,8 \\
\hline Média dos períodos & $62,3^{\mathrm{c}}$ & $58,3^{\mathrm{c}}$ & $77,5^{\mathrm{b}}$ & $61,0^{\mathrm{c}}$ & $121,5^{\mathrm{a}}$ & $116,5^{\mathrm{a}}$ & -- \\
\hline \multicolumn{8}{|c|}{ Ócio } \\
\hline 0 & 155,0 & 81,0 & 116,0 & 86,0 & 115,0 & 109,0 & 110,3 \\
\hline 33 & 169,0 & 97,0 & 120,0 & 88,0 & 113,0 & 113,0 & 116,7 \\
\hline 66 & 159,0 & 77,0 & 129,0 & 93,0 & 96,0 & 109,0 & 110,5 \\
\hline 99 & 161,0 & 74,0 & 116,0 & 94,0 & 104,0 & 105,0 & 109,0 \\
\hline Média dos períodos & $161,0^{\mathrm{a}}$ & $82,3^{\mathrm{c}}$ & $120,3^{b}$ & $90,3^{\mathrm{c}}$ & $107,0^{\mathrm{b}}$ & $109,0^{\mathrm{b}}$ & -- \\
\hline
\end{tabular}

Médias na mesma linha, seguidas de letras diferentes, diferem entre si $(\mathrm{P}<0,05)$ pelo teste de $\mathrm{SNK}$.

Não houve efeito dos tratamentos nos intervalos de tempo, tampouco interação entre os fatores (tempo e tratamento) sobre a variável tempo em ócio $(\mathrm{P} \geq 0,05)$. No entanto, os intervalos diferem entre si $(\mathrm{P}<0,05)$, observando-se maior tempo em ócio no período noturno, com pico de ocorrência para o intervalo de tempo de quatro-oito horas, correspondendo a $24 \%$ do tempo em que o animal permaneceu em ócio, ao passo que os intervalos oito-12 horas e 16-20 horas apresentaram menores tempos para a referida variável, fato esse justificado pelo fornecimento das dietas e, consequentemente, pela maior ocorrência da ingestão de alimentos.

\section{CONCLUSÃO}

A substituição de farelo de soja por farelo de crambe não afeta o comportamento ingestivo, embora, interfira negativamente, na eficiência da alimentação.

\section{AGRADECIMENTOS}

Os autores agradecem à Fundação de Amparo a Pesquisa do Estado de Minas Gerais - Fapemig; à Coordenação de Aperfeiçoamento de Pessoal de Nível Superior - Capes; e ao Conselho Nacional de Desenvolvimento Científico e Tecnológico - CNPq, pelo suporte financeiro para a execução deste trabalho. 


\section{REFERÊNCIAS}

ALBRIGHT, J.L. Feeding behavior of dairy cattle. $J$. Dairy Sci. v.76, p.485-498, 1993.

ALBRIGHT, J.L. Dairy animal welfare: current and needed research. J. Dairy Sci., v.70, p.2711-2718. 1987.

BUFFINGTON, D.E.; COLLAZO-AROCHO, A.; CANTON, G.H. et al. Black globe humidity index (BGHI) as comfort equation for dairy cows. Trans. Am. Soc. Agric. Biol. Eng., v.24, p.711-14, 1982.

BÜRGER, P.J.; PEREIRA, J.C.; QUEIROZ, A.C. et al. Comportamento ingestivo em bezerros holandeses alimentados com dietas contendo diferentes níveis de concentrado. Rev. Bras. Zootec., v.29, p.236-242, 2000 .

CARDOSO, R.B.; BINOTTI, F.F.S.; CARDOSO, E.D. Potencial fisiológico de sementes de crambe em função de embalagens e armazenamento. Pesqui. Agropecu. Trop., v.42, p.272-278, 2012.

CARVALHO, G.G.P.; PIRES, A.J.V.; RODRIGUES, R. et al. Comportamento ingestivo de ovinos Santa Inês alimentados com dietas contendo farelo de cacau. Rev. Bras. Zootec., v.37, p.660-665, 2008.

CASTRO, K.J. Torta de babaçu: consumo, digestibilidade, desempenho, energia metabolizável, energia líquida e produção de metano em ruminantes. 2012. 89f. (Tese- Doutorado) - Escola de Veterinária, Universidade Federal de Minas Gerais, Belo Horizonte, MG.

DADO, R.G.; ALLEN, M.S. Intake limitations, feeding behavior, and rumen function of cows challenged with rumen fill from dietary fiber or inert bulk. J. Dairy Sci., v.78, p.78-118, 1995.

DEGASPERI, S.A.R.; COIMBRA, C.H.; PIMPÃO, C.T. et al. Estudo do comportamento do gado Holandês em sistema de semi-confinamento. Rev. Acad.: Cienc. Agr. Amb., v.1, p.41-47. 2003.

DETMANN, E.; SOUZA, M.A.; VALADARES FILHO, S.C. et al. Métodos para análise de alimentos. Visconde do Rio Branco: Suprema, 2012. p.214.

FISCHER, V.; DESWYSEN, A.G.; DESPRES, L. et al. Comportamento ingestivo de Ovinos recebendo dieta à base de feno durante um período de seis meses. Rev. Bras. Zootec., v.5, p.1032-1038, 1997.

FISCHER, V.; DUTILLEUL, P.; DESWYSEN, A.G. et al. Aplicação de probabilidades de transição de estados dependentes do tempo na análise quantitativa do comportamento ingestivo de ovinos. Parte I. Rev. Bras. Zootec., v.29, p.1811-1820, 2000.

MARQUES, J.A.; MAGGIONI, D.; ABRAHAO, J.J.S. et al. Comportamento de touros jovens em confinamento alojados isoladamente ou em grupo. Arch. Latinoam. Prod. Anim., v.13, p.97-102, 2005.
MENDES, C.Q.; TURINO, V.F.; SUSIN, I. et al. Comportamento ingestivo de cordeiros e digestibilidade dos nutrientes de dietas contendo alta proporção de concentrado e diferentes fontes de fibra em detergente neutro. Rev. Bras. Zootec., v.39, p.594$600,2010$.

MENDONÇA, S.S.; CAMPOS, J.M.; VALADARES FILHO, S.C. et al. Comportamento ingestivo de vacas leiteiras alimentadas com dietas à base de cana-deaçúcar ou silagem de milho. Rev. Bras. Zootec., v.33, p.723-728, 2004.

MOUSQUER, C.M.; FERNANDES, G.A.; CASTRO, W.J.R. et al. Comportamento ingestivo de ovinos confinados com silagens. Rev. Bras. Hig. San. Anim., v.7, p.301-322, 2013.

NATIONAL REASEARCH COUNCIL - NRC. Nutrient requeriments of dairy catle. 7. ed. Washington, D.C.: National Academy Press, 2001. $381 \mathrm{p}$.

NEUMANN, M.; RESTLE, J.; MÜHLBACH, P.R.F. et al. Comportamento ingestivo de novilhos confinados com silagem de milho de diferentes tamanhos de partículas e alturas de corte. Ciênc. Anim. Bras., v.10, p.462-473, 2009.

OLIVEIRA, P.T.L.; TURCO, S.H.N.; ARAÚJO, G.G.L. et al. Comportamento ingestivo e parâmetros fisiológicos de bovinos Sindi alimentados com teores crescentes de feno de erva-sal. Rev. Bras. Cienc. Agr., v.7, p.180-188, 2012.

PAZDIORA, R.D.; BRONDANI, I.L.; SILVEIRA, M.F. et al. Efeitos da frequência de fornecimento do volumoso e concentrado no comportamento ingestivo de vacas e novilhas em confinamento. Rev. Bras. Zootec. v.40, p.2244-2251, 2011.

PINTO, A.P.; MARQUES, J.A.; ABRAHÃO, J.J.S. et al. Comportamento e eficiência ingestiva de tourinhos mestiços confinados com três dietas diferentes. Arch. Zootec. v.59, p.427-434, 2010.

SNIFFEN, C.J.; O'CONNOR, J.D.; VAN SOEST, P.J.; et al. A net carborhydrate and protein availability. J. of Anim. Sci., v.70, n.11, p.3562-3577, 1992.

STATISTICAL Analysis Systems. user's guide. Version 9.0. Cary, NC: SAS Institute Inc., 2002.

VALADARES FILHO, S.C.; AZEVÊDO, J.A.G.; PINA, D.S. et al. Consumo de matéria seca de bovinos nelores e mestiços. In: VALADARES FILHO, S.C.; PAULINO, P.V.R.; MAGALHÃES, K.A. Exigências nutricionais de zebuínos e tabela de composição de alimentos .Viçosa: UFV, 2006. 11p.

WELCH, J.G. Ingestión de alimentos y agua. In: CHURCH, C.D. El ruminante. fisiologia digestiva y nutricion. Zaragoza: Acribia, 1993. P.117-126. 